\title{
USO DE RESÍDUOS AGROINDUSTRIAIS DE CANA-DE-AÇÚCAR NA ADUBAÇÃO DA CULTURA DO MILHO
}

\section{USE OF RESIDUES FROM SUGARCANE AGRO INDUSTRY AS FERTILIZER IN CORN CROP}

\author{
Rogério Farinelli ${ }^{1}$, Iunis Eleodoro Mussi ${ }^{1}$ e Rafael Tadeu Alves Mancini ${ }^{1}$ \\ ${ }^{1}$ Centro Universitário da Fundação Educacional de Barretos (UNIFEB), Barretos, SP.
}

\begin{abstract}
Resumo
O trabalho consistiu em avaliar as características agronômicas e produtivas da cultura do milho para fins de produção de forragem e de grãos, em função de uso dos resíduos agroindustriais da cana-de-açúcar, associado com adubação mineral. O delineamento experimental foi o de blocos ao acaso, com sete tratamentos e quatro repetições, sendo os tratamentos representados por: uso de vinhaça concentrada; torta de filtro + cinza de caldeira; vinhaça + torta de filtro + cinza; vinhaça + adubação de cobertura; torta de filtro + cinza + adubação de cobertura; adubação mineral de semeadura e cobertura, e testemunha. $\mathrm{O}$ uso dos resíduos promoveu alterações na forragem e produtividade de grãos, com destaque para a adubação com vinhaça, associada à torta de filtro e cinza de caldeira, com produção de $45,5 \mathrm{t} \mathrm{ha}^{-1}$ de massa verde, $22,5 \mathrm{t} \mathrm{ha}^{-1}$ de massa seca e $8.109 \mathrm{~kg} \mathrm{ha}^{-1}$ de grãos.
\end{abstract}

Palavras-chave: Zea mays L., nitrogênio, vinhaça, torta de filtro, massa verde, produtividade.

\begin{abstract}
The present work aimed to evaluate the agronomic and yield characteristics of corn for forage and grains, when fertilized with agro-industrial sugarcane residues, associated with mineral fertilization, during 2011/2013 spring-summer. The experiment was designed in a randomized block scheme with seven treatments and four replications. The treatments consisted of: use of concentrated vinasse, filter cake associated with boiler ash, vinasse associated with filter cake and boiler ash, vinasse associated with topdressing fertilization, filter cake and boiler ash associated with topdressing fertilization, mineral sowing and topdressing fertilization, and control. The use of residues resulted in changes on forage and grain yield, especially for fertilization with concentrated vinasse associated with filter cake and boiler ash, with a production of $45,5 \mathrm{tha}^{-1}$ of green mass, $25,5 \mathrm{t} \mathrm{ha}^{-1}$ of dry mass and $8.109 \mathrm{~kg} \mathrm{ha}^{-1}$ of grains.
\end{abstract}

Key-words: Zea mays L., nitrogen, vinasse, filter cake, green mass, yield.

\footnotetext{
*Autor correspondente: Rogério Farinelli. Centro Universitário da Fundação Educacional de Barretos (UNIFEB), Avenida Professor Frade Monte, 389. CEP 14783-226, Barretos, SP. E-mail: rogerio.farinelli@unifeb.edu.br, 16-997099956
}

Recebido em: 26/10/2017

Aceito em: 03/05/2017 


\section{Introdução}

A importância econômica do milho está na sua diversidade de utilização, pois é usado desde a alimentação animal e humana, até a indústria de alta tecnologia. Contudo, o maior destino do milho é na produção de ração para a avicultura, a suinocultura e a bovinocultura, as quais são de grande importância econômica, tanto no âmbito mundial, como nacional.

Dentre os fatores que interferem na cultura do milho, o manejo da nutrição é um dos fatores preponderantes no aumento de produtividade de grãos. As quantidades de nutrientes que são extraídas pela cultura dependem da produtividade atingida, da cultivar, das condições de clima, da fertilidade do solo, da adubação realizada e dos demais tratos culturais. Trata-se de uma cultura que responde a altas adubações tanto na exploração para grãos quanto para a produção de silagem, desde que os demais fatores estejam em níveis ótimos, sendo o nitrogênio (N) o nutriente ao qual a cultura, geralmente responde em incrementos no rendimento de grãos (FORNASIERI FILHO, 2007).

Dados de extração de nutrientes nas diversas partes da planta do milho demonstram que a maior exigência refere-se ao N, elemento que apresenta maior perda principalmente quando mal manejado. Ele é constituinte de proteínas, enzimas, coenzimas, ácidos nucléicos, fitocromos e clorofila. Também afeta as taxas de iniciação e expansão foliar, e o tamanho final e a intensidade de senescência das folhas (FORNASIERI FILHO, 2007). Segundo Van Raij e Cantarella (1997), as recomendações em relação às épocas de aplicação de $\mathrm{N}$ no milho, para o Estado de São Paulo, para silagem são as mesmas que para a produção de grãos, ou seja, uma dose em semeadura de até $30 \mathrm{~kg} \mathrm{ha}^{-1} \mathrm{e}$ o restante em cobertura de até $120 \mathrm{~kg} \mathrm{ha}^{-1}$, podendo ser de uma a duas aplicações, conforme a dose recomendada.

Em relação ao potássio (K), embora não faça parte da estrutura química dos compostos da planta, este nutriente tem funções reguladoras nas células. Assim, deve-se dar atenção especial principalmente à produção de silagem, devido às grandes extrações deste nutriente. Desta forma, na semeadura, é necessário fornecer $60 \mathrm{~kg} \mathrm{ha}^{-1} \mathrm{e}$, em cobertura, até $160 \mathrm{~kg} \mathrm{ha}^{-1}$ de $\mathrm{K}_{2} \mathrm{O}$, mediante o teor de $\mathrm{K}$ no solo e estimativa de produtividade de matéria seca. Já o fósforo (P) é um dos nutrientes mais exportados, especialmente via grãos. Para cada tonelada de grãos produzida, são extraídos $9,2 \mathrm{~kg}$ de $\mathrm{P}_{2} \mathrm{O}_{5}$ e exportados $8,2 \mathrm{~kg}$ de $\mathrm{P}_{2} \mathrm{O}_{5}$, ou seja, $90 \%$ do total absorvido é removido via grãos. As recomendações da adubação fosfatada acompanham aquelas observadas para o $\mathrm{N}$, sendo fornecido via semeadura, com quantidades de até $100 \mathrm{~kg} \mathrm{ha}^{-1}$, em virtude do teor de P no solo e da estimativa de produtividade (VAN RAIJ; CANTARELLA, 1997).

Devido à crescente preocupação com a agricultura sustentável dos órgãos ligados ao meio ambiente, somada ao aumento dos preços dos fertilizantes, alavancou-se o desenvolvimento de tecnologias para a produção agrícola sustentável. Em muitas regiões, existe a possibilidade de aproveitamento de resíduos, os quais constituem opção interessante, quando bem utilizados (CARVALHO et al., 2011).

A agroindústria canavieira, por sua vez, é produtora de enormes quantidades de resíduos, os quais têm sido alvo, nos últimos anos, de especial atenção na agricultura, como agente condicionador das propriedades físicas, químicas e biológicas do solo. É importante ressaltar que tal interesse ocorre em virtude dos altos custos dos fertilizantes minerais.

Dentre esses resíduos, podem-se destacar três. O primeiro, a torta de filtro, que é um resíduo oriundo da filtração a vácuo do lodo retido nos clarificadores. É rica principalmente em $\mathrm{P}$, mas com concentrações expressivas de $\mathrm{Ca}, \mathrm{Mg}, \mathrm{Cu}$, $\mathrm{Zn}$ e $\mathrm{Fe}$, e possui relação $\mathrm{C} / \mathrm{N}$ muito elevada, podendo diminuir a disponibilidade de $\mathrm{N}$ no solo. Outro é a vinhaça, que é um resíduo produzido em grande quantidade nas destilarias de etanol. É rica especialmente em $\mathrm{K}$ e possui teores relativamente elevados de outros elementos, sendo que a composição desse resíduo é muito variável, dependendo das condições em que a usina vem operando. Se for considerado apenas o efeito do $\mathrm{K}$, pode-se dizer que praticamente $100 \%$ deste elemento está disponível para as plantas. Além da vinhaça e da torta de filtro, ainda há a cinza de caldeira, cujo material é rico em K, Ca e Mg. Esse resíduo é obtido através da queima do bagaço da cana-de-açúcar e, o destino corrente de cinza tem sido o solo, no qual vem sendo aplicada sem considerar a observância de critérios técnicos, como um simples material de descarte (CANELLAS et al., 2003; BRUNELLI; PISANI JÚNIOR, 2006; MODESTO et al., 2009). 
Os resíduos agroindustriais do setor canavieiro são, via de regra, utilizados nas próprias lavouras de cana-de-açúcar, tendo pouca empregabilidade em demais culturas, como, por exemplo, na cultura do milho, que necessita de grandes quantidades de nitrogênio e potássio para atingir seu potencial produtivo.

Alguns trabalhos da literatura têm obtido informações que podem auxiliar no uso desses resíduos para a nutrição mineral, a melhoria nas condições químicas do solo e produtividade do milho (SANTOS et al., 2006; BASSO et al., 2013).

Lima et al. (2012), estudando cinza de bagaço, torta de filtro, além de casca de arroz carbonizada e uma fonte mineral (silicato de cálcio), como fonte de silício $(\mathrm{Si})$, verificaram que o tratamento mais eficiente foi a casca de arroz carbonizada, que incrementou os teores de Si foliar em todas as doses; entretanto, independentemente do resíduo agroindustrial, observou-se que o teor de Si nas folhas de milho aumentou proporcionalmente com as dosagens, também. A aplicação de Si via fontes orgânicas não surtiu efeito na altura e na matéria seca da planta de milho, mas teve efeito significativo no diâmetro de colmo.

A avaliação da cinza da cana-de-açúcar pode se tornar útil na substituição da adubação química convencional, para produção de alimentos e preservação do meio ambiente (FEITOSA et al., 2009). Esses autores relataram que doses crescentes de cinza de bagaço de cana, nas doses de 60 a $90 \mathrm{t} \mathrm{ha}^{-1}$, podem substituir a adubação química recomendada para a cultura do milho de forma satisfatória. Além disso, concluíram que as cinzas de bagaço de cana se destacaram como eficientes em fonte de potássio e que ainda há necessidade de estudos, em condições de campo, para determinação da melhor forma de aplicação das cinzas de cana no solo.

Dessa forma, o objetivo do presente trabalho consistiu em avaliar as características agronômicas e produtivas da cultura do milho para fins de produção de forragem e de grãos, em função da aplicação dos resíduos agroindustrias da cana-de-açúcar, associada com adubação mineral.

\section{Material e Métodos}

$\mathrm{O}$ experimento foi instalado durante a safra primavera-verão 2011/2012, em condições de campo em Jaborandi-SP, em um solo classificado como Nitossolo vermelho eutrófico, apresentando latitude de $20^{\circ} 41^{\prime} 17^{\prime \prime}$, longitude de 48 24'45" e altitude de 493 metros. Segundo a classificação de Köeppen, o clima da região é do tipo Cwa, sendo definido como tropical de altitude, com inverno seco e verão quente e chuvoso.

Os resultados da análise química do solo da área experimental, na profundidade de 0-20 cm, apresentaram os seguintes valores: $\mathrm{pH}\left(\mathrm{CaCl}_{2}\right)=5,9 ;$ M.O. $\left(\mathrm{g} \mathrm{kg}^{-1}\right)=31 ; \mathrm{P}\left(\mathrm{mg} \mathrm{dm}^{-3}\right)=26$; $\mathrm{K}\left(\mathrm{mmol}_{\mathrm{c}} \mathrm{dm}^{-3}\right)=7,1 ; \mathrm{Ca}\left(\mathrm{mmol}_{\mathrm{c}} \mathrm{dm}^{-3}\right)=81 ;$ $\mathrm{Mg}\left(\mathrm{mmol}_{\mathrm{c}} \mathrm{dm}^{-3}\right)=26 ; \mathrm{H}+\mathrm{Al}\left(\mathrm{mmol}_{\mathrm{c}} \mathrm{dm}^{-3}\right)=20,7$; $\mathrm{SB}\left(\mathrm{mmol}_{\mathrm{c}} \mathrm{dm}^{-3}\right)=114,1 ; \mathrm{CTC}\left(\mathrm{mmol}_{\mathrm{c}} \mathrm{dm}^{-3}\right)=134,8$ e $\mathrm{V}(\%)=84,6$.

A área, anteriormente, estava em pousio e o solo foi preparado de forma convencional, com grade intermediária, subsolagem e, na sequência duas gradagens niveladoras. Para atender à necessidade de adubação para a produção de forragem e de grãos, foi fornecida a quantidade de $100 \mathrm{~kg} \mathrm{ha}^{-1} \mathrm{de}$ $\mathrm{N}, 50 \mathrm{~kg} \mathrm{ha}^{-1}$ de $\mathrm{P}_{2} \mathrm{O}_{5}$ e $40 \mathrm{~kg} \mathrm{ha}^{-1}$ de $\mathrm{K}_{2} \mathrm{O}$, com base na interpretação dos resultados da análise química do solo, para uma estimativa de produtividade de matéria verde de 30 a $40 \mathrm{t} \mathrm{ha}^{-1}$ e de 8 a $10 \mathrm{tha}^{-1}$ de grãos (VAN RAIJ; CANTARELLA, 1997).

O híbrido utilizado foi AG 1051, duplo, de ciclo semi-precoce (950 graus-dias), grão do tipo dentado, resistente ao acamamento, com aptidão para a produção de grãos, milho-verde e silagem, e nível de tecnologia média a alta. A semeadura foi realizada em 20/dez./2012, na densidade de 5,0 sementes por metro, perfazendo uma população inicial de 55.555 plantas ha $^{-1}$.

O delineamento experimental empregado foi o de blocos ao acaso, com sete tratamentos e quatro repetições. Os tratamentos constituíram-se de: vinhaça concentrada; torta de filtro+cinza de caldeira; vinhaça+torta de filtro+cinza de caldeira; vinhaça+adubação mineral de cobertura; torta de filtro+cinza de caldeira+adubação mineral de cobertura; adubação mineral de semeadura e cobertura. e testemunha (sem adubação). Cada parcela foi representada por quatro linhas de milho, espaçadas de $0,90 \mathrm{~m}$, com $6 \mathrm{~m}$ de comprimento, considerando como área útil apenas as duas linhas centrais. Os teores de $\mathrm{N}, \mathrm{P}_{2} \mathrm{O}_{5}$ e $\mathrm{K}_{2} \mathrm{O}$ presentes nesses nesses resíduos seguem na Tabela 1 .

Mediante as necessidades nutricionais da cultura do milho (VAN RAIJ; CANTARELLA, 1997), foram calculadas as quantidades aplicadas, de acordo com os tratamentos estudados (Tabela 2). 
Tabela 1- Composição química dos resíduos agroindustriais do processamento de cana-de-açúcar¹.

\begin{tabular}{|c|c|c|c|c|c|c|}
\hline \multirow{2}{*}{ Resíduos agroindustriais } & \multicolumn{2}{|c|}{$\mathbf{N}$} & \multicolumn{2}{|c|}{$\mathbf{P}_{2} \mathbf{O}_{5}$} & \multicolumn{2}{|c|}{$\mathrm{K}_{2} \mathrm{O}$} \\
\hline & $\left(\mathrm{kg} \mathrm{m}^{-3}\right)$ & $\left(\mathrm{g} \mathrm{kg}^{-1}\right)$ & $\left(\mathrm{kg} \mathrm{m}^{-3}\right)$ & $\left(\mathrm{g} \mathrm{kg}^{-1}\right)$ & $\left(\mathrm{kg} \mathrm{m}^{-3}\right)$ & $\left(\mathrm{g} \mathrm{kg}^{-1}\right)$ \\
\hline Vinhaça concentrada & 5,0 & -- & 0,06 & -- & 26,4 & -- \\
\hline Torta de filtro & -- & 13,9 & -- & 18,5 & -- & 2,4 \\
\hline Cinza de caldeira & -- & 2,5 & -- & 5,5 & -- & 15,0 \\
\hline
\end{tabular}

${ }^{1}$ Fonte: Usina Guarani - Unidade São José, Colina-SP.

Tabela 2- Tratamentos utilizados e respectivas quantidades aplicadas na cultura do milho.

\begin{tabular}{lc}
\hline \multicolumn{1}{c}{ Tratamentos } & Quantidades aplicadas \\
\hline Vinhaça concentrada & $1,51 \mathrm{~m}^{3} \mathrm{ha}^{-1}$ \\
Torta de filtro + cinza & $2,3 \mathrm{tha}^{-1}+2,3 \mathrm{tha}^{-1}$ \\
Vinhaça + torta + cinza & $1,51 \mathrm{~m}^{3} \mathrm{ha}^{-1}+2,3 \mathrm{tha}^{-1}+2,3 \mathrm{tha}^{-1}$ \\
Vinhaça + adubação de cobertura & $1,51 \mathrm{~m}^{3} \mathrm{ha}^{-1}+93 \mathrm{~kg} \mathrm{ha}^{-1} \mathrm{de} \mathrm{N}+50 \mathrm{~kg} \mathrm{ha}^{-1} \mathrm{de}_{2} \mathrm{O}_{5}$ \\
Torta + cinza + adubação de cobertura & $2,3 \mathrm{t} \mathrm{ha}^{-1}+2,3 \mathrm{tha}^{-1}+63 \mathrm{~kg} \mathrm{ha}^{-1} \mathrm{de} \mathrm{N}$ \\
Adubação mineral de semeadura + cobertura & $\begin{array}{c}\text { Semeadura com } 20,50 \mathrm{e} 40 \mathrm{~kg} \mathrm{ha}^{-1} \mathrm{de} \mathrm{N}_{\mathrm{P}} \mathrm{O}_{5} \text { e de K} \mathrm{O}, \\
\text { respectivamente e cobertura com } 80 \mathrm{~kg} \mathrm{ha}^{-1} \text { de N }\end{array}$ \\
Testemunha & Sem adubação \\
\hline
\end{tabular}

A aplicação dos resíduos agroindustriais foi realizada em área total antes da semeadura do milho, com posterior incorporação com grade niveladora. Já a adubação de cobertura foi realizada no estádio $\mathrm{V}_{6}$, quando as plantas apresentaram seis folhas totalmente expandidas, com a aplicação de ureia e super-fosfato simples em filete contínuo, a $10 \mathrm{~cm}$ de distância das plantas de milho.

Os tratamentos fitossanitários foram realizados mediante o desenvolvimento da cultura, na qual foi realizada a aplicação de herbicida pós-emergente (mesotriona), na dose de $192 \mathrm{~g}$ de ingrediente ativo ha ${ }^{-1}+0,5 \%$ de óleo mineral (adjuvante), e inseticida (lambdaciolotrina) na dose de 7,5 g de ingrediente ativo ha- ${ }^{-1}+0,5 \%$ de óleo mineral.

Durante a condução do experimento, foi avaliada no estádio $\mathrm{R}_{1}$ (florescimento feminino) em dez plantas ao acaso, por parcela, a área foliar (AF), utilizando os parâmetros de comprimento máximo do limbo (C), a largura máxima perpendicular à nervura principal do limbo foliar (L) e o produto do comprimento pela largura e por um fator de correção de $0,75(\mathrm{AF}=\mathrm{C} \times \mathrm{L} \times 0,75)$.

No estádio $\mathrm{R}_{5}$ (grão duro), foi avaliada a massa verde, determinada com a colheita de dez plantas na linha quando os grãos apresentaram de metade a um quarto amido líquido ("ponto de ensilagem"), sendo, em seguida, fracionadas em colmo + pendão, folhas e espigas, e assim pesados.
Para a avaliação da massa seca, as amostras fracionadas foram acondicionadas em sacos de papel e secas em estufa de circulação forçada de ar a $105^{\circ} \mathrm{C}$ até peso constante. Também nesse estádio fenológico, foi determinada, em dez plantas ao acaso por parcela, a altura de planta e a inserção de primeira espiga, com o auxílio de uma trena graduada, medindo-se a distância entre o colo da planta e a inserção do pendão, e a distância entre o colo da planta e a inserção da primeira espiga, respectivamente. $\mathrm{O}$ diâmetro de colmo foi avaliado por ocasião das determinações de altura de planta e de primeira espiga, utilizando-se um paquímetro no segundo entrenó acima da superfície do solo.

$\mathrm{Na}$ colheita da cultura do milho foram realizadas as avaliações do número de espigas por planta, do número de fileiras por espiga e de grãos por espiga, coletando-se 10 espigas por parcela, e procedendo-se à contagem. A massa de 100 grãos foi avaliada através de duas amostras de 100 grãos de milho da área útil da parcela experimental, com posterior pesagem e correção a $13 \%$ de umidade, determinada por meio do método da estufa a $105^{\circ} \mathrm{C} \pm 3^{\circ} \mathrm{C}$ por 24 horas (BRASIL, 2009).

A produtividade de grãos foi obtida por meio do processo de trilha das espigas contidas na área útil da parcela, com pesagem e correção a 13\% de umidade, determinada por meio do método da estufa a $105^{\circ} \mathrm{C} \pm 3^{\circ} \mathrm{C}$ por 24 horas (BRASIL, 2009). 
Os dados foram submetidos à análise de variância utilizando o Teste $\mathrm{F}$ e as médias dos tratamentos foram comparadas pelo Teste de Tukey $(\mathrm{p}<0,05)$, empregando o programa estatístico SISVAR (FERREIRA, 2011).

\section{Resultados e Discussão}

A área foliar não foi afetada pelos tipos de adubação, apresentando comportamento similar entre os tratamentos utilizados (Tabela 3). O aumento da área foliar reflete em folhas com maiores dimensões e isto pode promover o acréscimo de massa foliar e, consequentemente, da massa verde e seca da planta de milho. Acerca dessas relações, Fornasieri Filho (2007) afirmou que a produção de massa verde na cultura do milho está direcionada para algumas características morfológicas da planta, como, por exemplo, a altura, o número de folhas e a área foliar, como também o peso e o número de espigas. No entanto, esta relação não foi observada no presente trabalho.

Verifica-se que houve efeito significativo na produtividade de massa verde, destacando-se o tratamento com o uso de todos os resíduos agroindustriais produzindo o valor de 45,5 $\mathrm{tha}^{-1}$, valor este muito superior aos demais tratamentos. Para a massa seca, os tratamentos diferiram-se de forma mais expressiva do que para a massa verde, sendo novamente obtida superioridade na adubação com vinhaça associada à torta de filtro + cinza de caldeira (Tabela 3 ).

A associação destes três resíduos faz com que o fornecimento dos nutrientes à planta seja bastante satisfatório, pois são materiais com teores altos principalmente os macronutrientes primários, os quais são exigidos em maior quantidade pela cultura do milho. Castoldi et al. (2011), avaliando sistemas de cultivo e o uso de diferentes adubos (mineral, organomineral e orgânica) na produção de milho para silagem e para grãos verificaram que para a produção de silagem de planta inteira e massa seca da parte aérea, os sistemas e tampouco as adubações diferiram estatisticamente entre si, porém as exigências nutricionais foram supridas. Os autores ainda citaram que a ausência de superioridade para a adubação orgânica se deve ao primeiro ano de cultivo de milho e que se fazem necessários mais anos de condução dos estudos.

Contudo, Basso et al. (2013), estudando a vinhaça como fonte de K na sucessão aveia-preta/milho silagem/milho safrinha, observaram que para a cultura do milho, as doses de 100, 150 e $200 \mathrm{~m}^{3} \mathrm{ha}^{-1}$ de vinhaça foram estatisticamente superiores à adubação mineral, sendo, na dose de $200 \mathrm{~m}^{3} \mathrm{ha}^{-1}$, observada a maior produtividade de forragem $\left(58,6 \mathrm{t} \mathrm{ha}^{-1}\right)$. A menor produtividade de forragem $\left(51,5 \mathrm{tha}^{-1}\right)$ foi observada no tratamento sem suplementação de $\mathrm{K}$, ou seja, apenas com N+P mineral.

Para Lavezzo et al. (1997), a produção de massa seca está relacionada com a época de ensilagem, pois, com o desenvolvimento vegetativo da planta, aumenta-se a proporção de espigas e, portanto, o valor nutritivo da silagem. Por outro lado, quanto mais velha a planta, maior o teor de fibras nas folhas e colmos. Tal fato não ocorreu, pois todos

Tabela 3-Área foliar, massa verde e massa seca da parte aérea da cultura do milho, em função da aplicação de resíduos agroindustriais do processamento de cana-de-açúcar.

\begin{tabular}{|c|c|c|c|}
\hline Tratamentos & Área foliar & Massa verde & Massa seca \\
\hline & $\left(\mathbf{c m}^{2}\right)$ & $\left(\mathrm{t} \mathrm{ha}^{-1}\right)$ & $\left(\mathrm{t} \mathrm{ha}^{-1}\right)$ \\
\hline Vinhaça concentrada & 492,4 & $32,0 \mathrm{~b}$ & $17,9 \mathrm{~b}$ \\
\hline Torta de filtro+cinza & 530,9 & $33,2 \mathrm{~b}$ & $16,6 \mathrm{bc}$ \\
\hline Vinhaça + torta de filtro + cinza & 511,5 & $45,5 \mathrm{a}$ & $22,5 \mathrm{a}$ \\
\hline Vinhaça+adubação mineral de cobertura & 520,8 & $32,3 \mathrm{~b}$ & $16,1 \mathrm{bcd}$ \\
\hline Torta de filtro+cinza+adubação de cobertura & 530,7 & $30,2 \mathrm{~b}$ & $15,0 \mathrm{~cd}$ \\
\hline Adubação mineral de semeadura e cobertura & 534,9 & $33,0 \mathrm{~b}$ & $16,5 \mathrm{bc}$ \\
\hline Testemunha & 517,2 & $28,4 \mathrm{~b}$ & $14,1 \mathrm{~d}$ \\
\hline Teste F & $0,64^{\mathrm{ns}}$ & $22,01 * *$ & $31,38 * *$ \\
\hline CV $(\%)$ & 5,74 & 7,06 & 5,74 \\
\hline Média geral & 519,8 & 33,5 & 16,9 \\
\hline
\end{tabular}

Médias seguidas de letras distintas diferem entre si pelo Teste de Tukey $(\mathrm{p}<0,05)$. ${ }^{\text {ns }}$ não significativo; ${ }^{*}$ significativo a $5 \%$ e** significativo a $1 \%$. 
os tratamentos alcançaram o ponto de ensilagem no mesmo período.

Para as características morfológicas, também não houve diferença significativa entre os tratamentos (Tabela 4). Para a altura de planta e de inserção de espiga os valores obtidos estão de acordo com as informações do híbrido (CRUZ et al., 2012). Contudo, estas características estão relacionadas ao tipo de cultivar, ou seja, são parâmetros que são influenciados pelo fator genético.

No presente trabalho, a maior produção de forragem não associou a maior altura de planta $\mathrm{e}$ a área foliar. Mesmo não apresentando diferença significativa, o número de grãos por espiga e a massa de 100 grãos (Tabelas 5 e 6), que são componentes da produção, de certa forma, contribuíram para a maior produção de forragem no tratamento vinhaça + torta de filtro + cinza

Diante disso, Deminicis et al. (2009) confirmaram que a produção de forragem de alta qualidade depende da composição física das estruturas anatômicas da planta de milho, devendo apresentar em torno de $60 \%$ a $65 \%$ de espigas, o que define a participação em torno de $45 \%$ de grãos no material ensilado. A produção de forragem obtida no respectivo experimento (Tabela 3 ) foi calculada mediante as partes constituintes da planta de milho, sendo que todas as amostras continham as espigas.

Tabela 4-Altura de planta, altura de inserção de primeira espiga e diâmetro de colmo da cultura do milho, em função da aplicação de resíduos agroindustriais do processamento de cana-de-açúcar.

\begin{tabular}{|c|c|c|c|}
\hline \multirow[t]{2}{*}{ Tratamentos } & $\begin{array}{c}\text { Altura de } \\
\text { planta }\end{array}$ & $\begin{array}{c}\text { Altura de } \\
\text { primeira espiga }\end{array}$ & \multirow{2}{*}{$\begin{array}{c}\begin{array}{c}\text { Diâmetro de } \\
\text { colmo }\end{array} \\
(\mathrm{cm})\end{array}$} \\
\hline & \multicolumn{2}{|c|}{--------(m) -------- } & \\
\hline Vinhaça concentrada & 2,3 & 1,2 & 1,9 \\
\hline Torta de filtro+cinza & 2,3 & 1,1 & 2,0 \\
\hline Vinhaça + torta de filtro+cinza & 2,2 & 1,2 & 1,9 \\
\hline Vinhaça+adubação mineral de cobertura & 2,3 & 1,2 & 2,1 \\
\hline Torta de filtro+cinza+adubação de cobertura & 2,3 & 1,2 & 2,0 \\
\hline Adubação mineral de semeadura e cobertura & 2,2 & 1,2 & 2,1 \\
\hline Testemunha & 2,2 & 1,1 & 1,8 \\
\hline Teste F & $0,64^{\mathrm{ns}}$ & $1,46^{\mathrm{ns}}$ & $2,23^{\mathrm{ns}}$ \\
\hline CV $(\%)$ & 4,27 & 5,91 & 7,62 \\
\hline Média geral & 2,3 & 1,2 & 2,0 \\
\hline
\end{tabular}

Tabela 5-Número de espigas por planta, fileiras por espiga e grãos por espiga da cultura do milho, em função da aplicação de resíduos agroindustriais do processamento de cana-de-açúcar.

\begin{tabular}{|c|c|c|c|}
\hline \multirow[t]{2}{*}{ Tratamentos } & $\begin{array}{c}\text { Espigas por } \\
\text { planta } \\
\end{array}$ & $\begin{array}{c}\text { Fileiras } \\
\text { por espiga }\end{array}$ & Grãos por espiga \\
\hline & \multicolumn{3}{|c|}{ 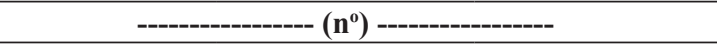 } \\
\hline Vinhaça concentrada & 1,0 & 15,0 & 419,0 \\
\hline Torta de filtro+cinza & 1,0 & 15,0 & 447,0 \\
\hline Vinhaça + torta de filtro + cinza & 1,0 & 14,0 & 451,0 \\
\hline Vinhaça+adubação mineral de cobertura & 1,0 & 15,0 & 437,0 \\
\hline Torta de filtro+cinza+adubação de cobertura & 1,0 & 15,0 & 422,0 \\
\hline Adubação mineral de semeadura e cobertura & 1,0 & 16,0 & 454,0 \\
\hline Testemunha & 1,0 & 15,0 & 434,0 \\
\hline Teste F & -- & $0,65^{\text {ns }}$ & $0,31^{\mathrm{ns}}$ \\
\hline $\mathrm{CV}(\%)$ & -- & 5,29 & 11,27 \\
\hline Média geral & -- & 15,0 & 438,0 \\
\hline
\end{tabular}

Médias seguidas de letras distintas diferem entre si pelo Teste de Tukey $(\mathrm{p}<0,05)$. ${ }^{\text {ns }}$ não significativo; * significativo a $5 \%$ e** significativo a $1 \%$. 
Os valores para o número de grãos por espiga, bem como para a massa de 100 grãos, não apresentaram diferenças significativas entre os tratamentos estudados, pois são componentes fortemente influenciados pela disponibilidade hídrica nos estádios de formação e enchimento de grãos. Como não houve déficit hídrico para a cultura, esses resultados podem estar relacionadoscom a nutrição da cultura em estádios anteriores à formação do grão. Tal fato corrobora com os resultados de Santos et al. (2006).

Beleze et al. (2003) explicaram que, embora a seleção de híbridos para produção de silagem de milho tenha sido baseada em produção de grãos e de MS total, outros componentes da planta como sabugo, colmo, folhas e palhas, não têm sido devidamente avaliados.

Em relação à produtividade de grãos, novamente a adubação utilizando vinhaça + torta de filtro + cinza promoveu o maior valor (Tabela 6), com ganho de $1.371 \mathrm{~kg} \mathrm{ha}^{-1}(16,9 \%)$ quando comparado ao valor obtido pela testemunha sem adubação, e $1.105 \mathrm{~kg} \mathrm{ha}^{-1}(13,6 \%)$ com a adubação mineral. Mesmo sendo um híbrido duplo, com potencial genético menor em relação aos híbridos simples, a produtividade é acrescida quando o genótipo é submetido a condições de ambiente superiores, ou neste caso, de melhor fertilização. Nota-se novamente uma amplitude de resultados bastante distintos, sendo que na ausência de adubação a produtividade foi menor, e o uso exclusivo da adubação mineral (semeadura + cobertura) de maneira geral não foi suficiente para superar a adubação com os resíduos agroindustriais da cana-de-açúcar.

A vinhaça trouxe benefícios para a cultura do milho, tanto para a produção de forragem quanto para a produção de grãos. Atualmente, a fertirrigação com vinhaça é uma prática muito comum entre as usinas e destilarias do Brasil, trazendo resultados positivos para a produtividade da agricultura e gerando, ainda, economia com fertilizantes, repondo alguns nutrientes no solo, como, neste caso, $\mathrm{K}_{2} \mathrm{O}$ e MgO. E, segundo Santos et al. (2006), a vinhaça, quando adicionada ao solo, contribui também para o aumento do $\mathrm{pH}$ e o aumento na disponibilidade de fósforo.

Basso et al. (2013) verificaram que a utilização da vinhaça como fonte de $\mathrm{K}$ na sucessão 'aveia preta-milho silagem-milho safrinha' pode substituir a adubação mineral com KCL e com residual para os cultivos subsequentes. Quando se compara a produtividade de grãos de milho safrinha para as diferentes doses de vinhaça, a maior produtividade $\left(5,1\right.$ tha $\left.^{-1}\right)$ foi observada na aplicação de $100 \mathrm{~m}^{3} \mathrm{ha}^{-1}$, ou seja, um incremento de $41 \%$ na produtividade, quando comparado ao tratamento de adição de K.

Além disso, Korndorfer e Anderson (1997) relataram que outros resíduos, como a torta de filtro, possuem a capacidade de alterações nos atributos químicos do solo, como aumento na disponibilidade de $\mathrm{P}, \mathrm{Ca}$ e N , aumento nos teores de C orgânico e na CTC, e diminuição nos teores de Al trocável. Isto provavelmente pode ter ocorrido no experimento, o que mostra também o potencial de uso desse resíduo na produção agrícola.

Tabela 6-Massa de 100 grãos e produtividade de grãos da cultura do milho, em função da aplicação de resíduos agroindustriais do processamento de cana-de-açúcar.

\begin{tabular}{lccc}
\hline \multirow{2}{*}{ Tratamentos } & Massa de 100 grãos & Produtividade de grãos \\
\cline { 2 - 3 } & $\mathbf{( g )}$ & $\mathbf{k g ~ h a}^{-1} \mathbf{)}$ \\
\hline Vinhaça concentrada & 32,5 & $6.639 \mathrm{~g}$ \\
Torta de filtro+cinza & 35,0 & $7.635 \mathrm{c}$ \\
Vinhaça+torta de filtro+cinza & 36,8 & $8.109 \mathrm{a}$ \\
Vinhaça+adubação mineral de cobertura & 35,0 & $7.672 \mathrm{~b}$ \\
Torta de filtro+cinza+adubação de cobertura & 33,7 & $6.863 \mathrm{e}$ \\
Adubação mineral de semeadura e cobertura & 33,7 & $7.004 \mathrm{~d}$ \\
Testemunha & 31,8 & $6.738 \mathrm{f}$ \\
Teste F & $1,74^{\text {ns }}$ & $8740,38^{* *}$ \\
CV (\%) & 7,49 & 6,17 \\
Média geral & 34,1 & 7.237 \\
\hline
\end{tabular}

Médias seguidas de letras distintas diferem entre si pelo Teste de Tukey $(\mathrm{p}<0,05)$. ${ }^{\text {ns }}$ não significativo; * significativo a $5 \%$ e** significativo a $1 \%$. 
Segundo Brunelli e Pisani Júnior (2006), a utilização da cinza como insumo no processo produtivo agrícola é ambiental e economicamente viável, uma vez que esse material possibilita alta capacidade de retenção de água, melhorando o desenvolvimento da cultura e reduzindo impactos ambientais provocados pela irrigação. Outra vantagem consiste no fato este material ser fonte de macro e micronutrientes, além de ser potencialmente capaz de corrigir o teor de acidez do solo, tendo $1.000 \mathrm{~kg}$ de cinza efeito equivalente a $500 \mathrm{~kg}$ de calcário.

Vale ressaltar que, no processo de produção de silagem de milho, ao contrário da produção de grãos, há uma grande exportação de macronutrientes, principalmente o nitrogênio, mas também de outros, como: potássio, enxofre, cálcio e magnésio, o que justifica maiores investimentos em adubação de base e/ou cobertura para o milho destinado à silagem (VAN RAIJ; CANTARELLA, 1997; FRANÇA; COELHO, 2005). Daí a importância de buscar alternativas para nutrição do milho, uma vez que a adubação mineral gera custos elevados, empregando-se outras fontes que, além de fornecer os nutrientes necessários à cultura, garantem também melhorias no solo, tanto em atributos químicos quanto físicos.

Contudo, este tipo de adubação ainda não é muito aplicado, pois a utilização desses resíduos em larga escala ainda não é possível, pois as usinas disponibilizam pouco aos produtores que fornecem a cana a estas, e também dependendo da localização da propriedade, fica inviável tal disponibilização, pois o custo com o transporte sairia superior ao da adubação mineral. Com a importância da indústria canavieira, se faz essencial a busca por uma produção sustentável, fazendo-se necessárias pesquisas relacionadas a esse segmento.

\section{Conclusão}

A aplicação dos resíduos, especialmente vinhaça + torta de filtro + cinza como fertilizantes na cultura do milho, mostrou-se eficiente, obtendo melhores resultados para a produção de forragem e de grãos.

\section{Referências}

BASSO, C. J. et al. Vinhaça como fonte de potássio: resposta da sucessão aveia-preta/milho silagem/ milho safrinha e alterações químicas do solo na Região Noroeste do Rio Grande do sul. Ciência Rural, v. 43, n. 4, p. 596-602, 2013.
BELEZE, J. R. F.; ZEOULA, L. M. I.; CECATO, U. Avaliações de cinco híbridos de milho (Zea mays L.) em diferentes estádios de maturação. 1. Produtividade, características morfológicas e correlações. Revista Brasileira de Zootecnia, v. 32, n. 3, p. 529-537, 2003.

BRASIL. Ministério da Agricultura, Pecuária e Abastecimento. Secretaria de Defesa Agropecuária Coordenação Geral de Apoio Laboratorial. Regras para análise de sementes. In: . Determinação do grau de umidade. Brasília: Ministério da Agricultura, Pecuária e Abastecimento, 2009.398 p.

BRUNELLI, A. M. M. P.; PISANI JÚNIOR, R. Proposta de disposição de resíduo gerado a partir da queima do bagaço de cana-de-açúcar em caldeiras como fonte de nutriente e corretivo do solo. In: CONGRESO INTERAMERICANO DE INGENIERÍA SANITARIA Y AMBIENTAL, 30., 2006, Punta del Leste. Anais... Punta del Leste: Asciación Interamer Cana-de-açucar de Ingeniería Sanitaria y Ambiental, 2006. v.1, p.1-9.

CANELLAS, L. P. et al. Propriedades químicas de um Cambissolo cultivado com cana-de-açúcar, com preservação do palhiço e adição de vinhaça por longo tempo. Revista Brasileira de Ciência do Solo, v. 27, n. 5, p. 935-944, 2003.

CARVALHO, E. R. et al. Fertilizante mineral e resíduo orgânico sobre características agronômicas da soja e nutrientes do solo. Revista Ciência Agronômica, v. 42, n. 4, p. 930-939, 2011.

CASTOLDI, G. et al. Sistemas de cultivo e uso de diferentes adubos na produção de silagem de grãos de milho. Acta Scientiarum, v. 33, n. 1, p. 139-146, 2011.

CRUZ, J. C.; PEREIRA FILHO, I. A.; SILVA, G. H. Milho-cultivares para 2011/2012. Disponível em: $<$ http:www.cnpms.embrapa.br $>$. Acesso em: 12 dez. 2012.

DEMINICIS, B.B.; VIEIRA, H.D.; JARDIM, J.G.; ARAÚJO, S.A.C.; CHAMBELA NETO, A.; OLIVEIRA, V.C.; LIMA, E.S. Silagem de milho: características agronômicas. Revista Eletrônica de Veterinária, Garça, v. 10, n. 2, p. 120-125, 2009.

FEITOSA, D.; AMTONI, K. L.; SILVA, I. P. F Avaliação da cinza, oriunda da queima do bagaço da cana de açúcar, na substituição da adubação 
química convencional para produção de alimentos e preservação do meio ambiente. Revista Brasileira de Agroecologia, v. 4, n. 2, p. 2412-2415, 2009.

FERREIRA, D. SISVAR software: versão 5.3. Lavras: DEX/UFLA, 2011. Software.

FORNASIERI FILHO, D. Manual da Cultura do Milho. Jaboticabal: Funep, 2007. 576 p.

FRANÇA, G. E.; COELHO, A. M. Adubação do milho para silagem. In: CRUZ, J. C. et al. (Ed.). Produção e utilização de silagem de milho e sorgo. 2. ed. Sete Lagoas: Embrapa Milho e Sorgo, 2005. p. 53-83.

KORNDORFER, G. H.; ANDERSON, D. L. Use and impact of sugar-alcohol residues vinasse and filter on sugarcane production in Brazil. Sugar y azucar, v. 3, n. 92, p. 26-35, 1997.

LAVEZZO, W.; LAVEZZO, O. E. N.; CAMPOS NETO, O. Estádio de desenvolvimento do milho.

1. Efeito sobre a produção, composição da planta e qualidade da silagem. Revista Brasileira de Zootecnia, v. 26, n. 4, p. 675-682, 1997.
LIMA, P. H. et al. Resíduos orgânicos agroindustriais como fonte de Si para a cultura do milho. In: CONGRESSO NACIONAL DE MILHO E SORGO, 29., 2012, Águas de Lindóia. Anais... Águas de Lindóia: Associação Brasileirea de Milho e Sorgo, 2012. p. 1698-1704.

MODESTO, P. T. et al. Alterações em algumas propriedades de um latossolo degradado com o uso de logo de esgoto e resíduos orgânicos. Revista Brasileira de Ciência do Solo, v. 33, n. 5, p. 1489-1498, 2009.

VAN RAIJ, B.; CANTARELLA, H. Milho para grãos e silagem. In: RAIJ VAN, B.; CANTARELLA, H.; QUAGGIO, J. A.; FURLANI, A. M. C. Recomendações de adubação e calagem de milho para grãos e silagem para o Estado de São Paulo. 2. ed. Campinas: Instituto Agronômico: Fundação IAC, 1997. p. 56-59. (Boletim Técnico, 100).

SANTOS, J. R. et al. L Atributos químicos do solo e produtividade do milho afetados por corretivos e manejo de solo. Revista Brasileira 